\title{
A DECISÃO DE TRADUZIR O PRÓPRIO TEXTO, MOTIVAÇÕES E CONSEQUÊNCIAS: UM BREVE ESTUDO DOS CASOS DOS ESCRITORES BRASILEIROS ANA MARIA MACHADO E JOÃO UBALDO RIBEIRO ${ }^{1}$
}

\author{
Maria Alice Antunes \\ Bianca Walsh
}

\section{Introdução}

A decisão de traduzir o próprio texto pode ser atribuída a diversas razões desde o desejo de ver a obra atingir um público leitor maior até o desejo de publicação em um país estrangeiro de uma obra proibida na terra natal de um escritor. As consequências dessa decisão, contudo, não são muito variadas. Em geral, a autotradução (e a publicação do texto autotraduzido) pode tornar o autotradutor parte do sistema literário que recebe a autotradução ou pode aumentar o respeito ao escritor no sistema literário de origem. Neste artigo, pretendemos apresentar uma análise das razões que levam um autor a traduzir a própria obra além de apresentar as consequências que a tradução do próprio texto traz para os autotradutores. Para ilustrar tais motivos e consequências, discutiremos os casos de dois escritores brasileiros, membros da Academia Brasileira de Letras: Ana Maria Machado e João Ubaldo Ribeiro.

Como Julio Cesar Santoyo (2006, p. 25), acreditamos que a autotradução não é um fenômeno tão raro, conforme declaração de Antoine Berman (1992), entre outros. A autotradução é, na verdade, uma atividade que muitos autores exercem. Em seu artigo intitulado "Autotraducciones: Una Perspectiva Histórica", Julio Cesar Santoyo argumenta que a autotradução está presente na história da tradução desde que o historiador judeu Flavio Josefo escreveu a história da destruição de Jerusalém em sua língua nativa e depois traduziu-a - ele mesmo - para o grego (2005, p. 859). Também Hokenson e Munson afirmam que "uma lista de autotradutores reuniria os principais autores de muitas literaturas e línguas" (2007, p. 1). Na verdade, os ganhadores do Prêmio Nobel Frédéric Mistral (1904), Rabindranath Tagore (1913), Samuel Beckett (1969), Isaac Bashevis Singer (1978), Czeslaw Milosz (1980) e Joseph Brodsky (1987) são só alguns dos “principais autores” que traduziram a

\footnotetext{
${ }^{1}$ Partes deste artigo foram apresentadas no Colóquio internacional "Autotraduction. Frontières de la langue et de la culture", realizado em Perpignan, de 20 a 21 de outubro de 2011.
} 
ANTUNES \& WALSH - A decisão de traduzir o próprio texto...

própria obra para o francês ou para o inglês (Santoyo 2005, p. 864; Grutman 2009, p. 126).

Outro fato que corrobora a relevância do fenômeno da autotradução é a necessidade de expressão em outras línguas. Nos países em que há mais de uma língua oficial, por exemplo, os sistemas literários reproduzem essa diversidade. Por outro lado, considerando que a língua inglesa funciona como língua franca na ciência, pesquisadores do mundo todo precisam traduzir seus próprios artigos para esse idioma, se quiserem tornar suas descobertas conhecidas. A língua inglesa é usada por mais de 300 milhões de pessoas como língua nativa e por mais de 700 milhões de pessoas como segunda língua (Grutman 2009, p. 126).

No entanto, apesar de sua presença, a autotradução é "uma área praticamente esquecida dos estudos da tradução" (Santoyo 2006, p. 22). Recentemente, o interesse na área tem aumentado, mas ainda há lacunas a respeito de diversas questões relacionadas ao tema:

falta de atenção a questões de ideologia; questões relacionadas a restrições de natureza sistêmica; as línguas vistas como minoritárias e seu papel vis-à-vis as línguas vistas como majoritárias; acesso a mercados literários, público leitor e recursos maiores; questões de "modas" literárias que valorizam determinadas literaturas "exóticas" (Filippakopoulou 2005, p. 24).

Este artigo contribui para o preenchimento desse espaço ao discutir razões que fazem escritores brasileiros optar pela tradução do próprio trabalho para o inglês e as consequências dessa decisão. Ao discutir tais razões e consequências, esperamos demonstrar que a autotradução não acontece em um vácuo, ou em um ambiente livre de pressões.

O artigo está organizado da seguinte forma. Na próxima seção, apresentamos algumas das razões que explicam a opção pela autotradução. Em seguida, tratamos das consequências dessa opção para depois apresentar uma análise mais detalhada dos casos de Ana Maria Machado e João Ubaldo Ribeiro.

\section{Razões pessoais e razões externas}

No artigo "Translation, Self-translation and Apartheid-imposed Conflict", Alet Kruger afirma que 
ANTUNES \& WALSH - A decisão de traduzir o próprio texto...

de acordo com Brink (1983, p.113), "motivos pessoais" tais como o desejo de "dizer" o romance em uma nova língua e "motivos externos" tais como a recusa a ser silenciado por causa da censura e a tentativa de reter seu público leitor já estabelecido, foram responsáveis pelo começo do processo de autotradução que se transformou em sua marca registrada (2008, p. 6).

Por outro lado, Stephen Kellman afirma que "nenhuma pressão externa forçou Beckett, que já publicava trabalhos importantes em inglês, a mudar para o francês, exceto o desafio perverso de renunciar às vantagens da fluência nativa" (2003, p. xiii). Parece-nos importante ressaltar nessas afirmativas o fato de que ambos, Kruger e Kellman, admitem a existência de dois tipos de motivos para a opção pela autotradução: "razões pessoais" e "razões externas". Sobre a afirmativa de Kellman, é importante destacar que é pouco provável que "nenhuma razão externa motivou Beckett a mudar para o francês" e, consequentemente, traduzir as próprias obras para o inglês. Na verdade, muito pouco foi dito até hoje sobre possíveis razões externas e sobre as pressões de natureza sistêmica que levaram Beckett a traduzir suas obras do francês para o inglês, principalmente. Como Rainier Grutman demonstra, "ao estudar Beckett se conhece Beckett cada vez melhor, o mais famoso de uma série de autotradutores estudado em esplêndido isolamento" (2009, p. 125).

É essencial levar em conta que a autotradução não acontece em uma espécie de vácuo onde só o escritor e suas razões pessoais atuem. Pressões de natureza sistêmica precisam ser consideradas, já que exercem um papel central na opção pela autotradução. Em seu estudo sobre o papel da tradução e da autotradução nas carreiras de autores africanos de destaque, Kruger afirma que "o fenômeno não pode ser estudado em isolamento" (2008, p. 2). Sobre os autotradutores que ganharam o Prêmio Nobel, Grutman pergunta: "é pura coincidência que todos, sem exceção, construíram parte de sua obra em inglês e que a metade entre eles também escreveu em francês?" (2009, p. 125).

Contudo, um escritor não traduzirá a própria obra se não tiver uma razão pessoal forte para fazê-lo. Como podemos ver no estudo de Kruger, outros autores africanos, tais como Breyten Breytenback, Etienne van Heerden, John Miles, entre outros, tiveram suas obras traduzidas para várias línguas (2008, p. 8), mas nenhum desses traduziu a própria obra.

Entre as razões pessoais apresentadas por pesquisadores, temos: "o desejo de ‘dizer' a obra em uma língua diferente” (Kruger 2008, p. 6); “o desejo de alcançar um 
ANTUNES \& WALSH - A decisão de traduzir o próprio texto...

público leitor maior" (Asaduddin 2008, p. 236); “o desejo de ter acesso à visibilidade e à existência literárias" (Casanova 2002, p. 135); “o receio de uma representação distorcida" (Asaduddin 2008, p. 236); o desejo de "conseguir liberdade literária mantendo controle sobre a forma dos textos e assim reivindicar autonomia absoluta" (Casanova 2002, p. 142); "o desafio de renunciar às vantagens da fluência nativa" (Kellman 2003, p. xiii); a migração (Kellman 2003, p. xii); o desejo de adotar posições políticas ou ideológicas (Ehrlich 2007, p. 17) e a transformação da autotradução em "uma etapa (quase) essencial do processo criativo" (Ehrlich 2007, p. 17). Os autotradutores, por sua vez, apresentam como razões para a opção pela autotradução a aversão às traduções já feitas e publicadas (Nabokov apud Scheiner, 2002; Kundera 1992, p. 322). Raymond Federman afirma que "o livro parece inacabado se não existe na outra língua" (Federman 2000).

As razões externas apresentadas por pesquisadores incluem o exílio (Ehrlich 2007, p. 17); a censura (Kruger 2008, p. 6); o fato de que "a autotradução torna-se uma marca registrada" (Kruger 2008, p. 6); o fruto do trabalho de um agente literário (Antunes 2009, p. 166); interesse comercial (Ehrlich 2007, p. 17) e o fato de que pode haver muito poucos tradutores profissionais aptos a traduzirem de uma língua específica (Casanova 2002, p. 137).

A combinação dos dois tipos de razões atua quando um escritor escolhe a autotradução. Um escritor que usa a autotradução como uma ferramenta política ou ideológica quase sempre faz isso porque o contexto o "encoraja" a fazê-lo. Esse é muitas vezes o caso dos escritores exilados. Muitos deles continuam a escrever na língua materna e traduzem seus trabalhos para a segunda língua. O escritor queniano, professor da Universidade da California, Ngugi Wa Thiong'o, é um exemplo disso.

É importante ressaltar também que ambas as razões pessoais e as razões externas tendem a revelar características do contexto sócio-histórico e do polissistema literário do qual o escritor é parte. Chegar a um público leitor maior é muitas vezes o desejo de escritores pertencentes a polissistemas literários não hegemônicos que escrevem em uma língua não hegemônica. Bernardo Atxaga, escritor e tradutor de seus romances em parceria com a tradutora profissional (e sua esposa) Asun Garikano, é um exemplo disso. Atxaga escreve seus romances na língua basca, não hegemônica, e os traduz em parceria com Garikano para o castelhano, uma língua vista como hegemônica se comparada ao idioma basco, em especial. Um escritor que 
ANTUNES \& WALSH - A decisão de traduzir o próprio texto...

decide traduzir o próprio texto por causa de qualquer uma das razões pessoais que descrevemos terá seu trabalho publicado se há interesse comercial na obra ou se o trabalho é visto como uma resposta a uma pressão do polissistema literário, como nos casos dos brasileiros Ana Maria Machado e João Ubaldo Ribeiro. Examinemos agora as consequências da autotradução.

\section{Consequências da autotradução}

As consequências da autotradução não foram muito exploradas na literatura. Aquelas que apresentaremos aqui estão presentes nos casos dos escritores provenientes de países distintos que decidem traduzir o próprio texto.

Em primeiro lugar, destacamos que a autotradução - e a publicação da obra pode afetar o sistema literário alvo. Samuel Beckett é um exemplo de um autotradutor cujo trabalho tornou-o parte de dois cânones literários: o francês e o inglês. Como argumenta Brian Fitch,

a maior parte dos críticos francófonos tende a tratar os textos [de Beckett] como originais em francês e a maioria dos críticos ingleses trata todos os seus textos como originais em inglês, sem fazer qualquer referência à existência de um texto anterior em uma língua estrangeira (1988, p. 124).

Em segundo lugar, pode-se perceber que a autotradução permitiu que vários autores tivessem uma carreira literária internacional. Se tivessem decidido escrever na língua nativa (e não hegemônica) - gikuyu e basco - as obras de Thiong'o e Atxaga dificilmente teriam ultrapassado as fronteiras do Quênia e do País Basco, respectivamente.

Outra possível consequência da autotradução é o controle total sobre o texto autotraduzido e a consequente autonomia que o escritor alcança (Casanova 2002, p. 142). Se a autotradução é parte do processo criativo do escritor, como nos casos de André Brink e Ngugi Wa Thiong'o, o controle e a autonomia são absolutos. Se a tradução é feita por tradutores que tem uma relação familiar com os autores, o controle pode ser quase total. As declarações de Vladimir Nabokov sobre o trabalho do tradutor, seu filho Dmitri, comprovam esse fato. Nabokov classificava o filho como um "tradutor dócil” (Antunes 2009, p. 92).

Finalmente, é verdade que, em geral, a autotradução (e a divulgação desse trabalho na mídia) aumenta o respeito pelo escritor no sistema literário de origem. 
ANTUNES \& WALSH - A decisão de traduzir o próprio texto...

João Carlos Teixeira Gomes (2005) destaca a "tarefa hercúlea" (p. 75) e a "façanha inédita" (p. 75) que João Ubaldo Ribeiro assumiu ao verter seus romances para o inglês e afirma ainda que "não conhece proeza literária igual” (p. 75).

\section{Os casos de Ana Maria Machado e João Ubaldo Ribeiro}

Ana Maria Machado nasceu no Brasil em 1941. Foi professora, escritora de artigos para revistas e tradutora. Machado faz parte de um grupo de autores brasileiros que se tornaram tradutores e que por isso tiveram papel importante na formação dos primeiros leitores brasileiros com suas traduções dos clássicos da literatura infantojuvenil (Nascimento 2012, p. 45). Apesar de tradutora experiente, coube à sua filha Luisa Baeta a tradução de Do Outro Mundo (2002) / From Another World (2005) para o inglês. Esta foi também a primeira obra de Machado traduzida para a língua de Shakespeare. A tradução deu-se por iniciativa da editora canadense Grounwood Books depois da escritora brasileira ter recebido o prêmio Hans Christian Andersen, considerado o prêmio Nobel da literatura infantil mundial (Nascimento 2012, p. 44). Segundo Verônica Suhett Nascimento, a editora sugeriu que a própria Ana Maria Machado fizesse a tradução, mas a escritora recusou-se a executar a tarefa por não dispor do tempo necessário e por não se sentir "confortável traduzindo para uma língua que não a sua nativa" (p. 46). Entretanto, a ideia de manter controle sobre a tradução e a possibilidade de acompanhar a tarefa bem de perto atraíram a autora (p. 46). Assim, a filha de Ana Maria Machado fez seu primeiro e único trabalho de versão do português para o inglês, acompanhada "bem de perto" pela autora.

Vemos assim que a autotradução tal como praticada por Ana Maria Machado assemelha-se tanto à atividade praticada por Vladimir Nabokov, que traduziu a maioria de seus romances em parceria com o filho, quanto à autotradução praticada por Bernardo Atxaga, que traduz seus romances para o castelhano em parceria com a esposa. Os laços familiares com os tradutores e a consequente proximidade entre autor e tradutor permitem um maior controle sobre a tradução e a palavra final sobre o projeto tradutório. Sobre o caso de Ana Maria Machado, a tradutora Luisa Baeta afirma (via chat do Facebook) "houve uma discussão sobre como traduzir termos muito específicos da realidade brasileira que apareciam no texto". Tal discussão contou com a tradutora, a editora e Ana Maria Machado. A decisão final adotada foi a de "manter alguns desses termos em português e incluir um glossário no final". 
ANTUNES \& WALSH - A decisão de traduzir o próprio texto...

Outros livros de literatura infanto-juvenil de autoria de Ana Maria Machado foram traduzidos para o inglês (por outros tradutores) e publicados, mas não apresentam glossários.

Destacamos ainda, no caso de Do Outro Mundo, que a iniciativa para a publicação da obra em inglês foi da editora, fato pouco comum no caso da circulação da literatura brasileira em geral. Parece evidente que o prêmio Hans Christian Andersen pressionou a primeira tradução e posterior publicação da obra em inglês. Como veremos adiante, o trabalho do agente literário costuma ser essencial no processo de publicação da literatura brasileira no exterior.

Em contrapartida, as consequências da autotradução, no caso de Ana Maria Machado, foram o acesso específico ao sistema literário de língua inglesa e o controle quase total do processo tradutório. No que tange ao acesso a sistemas literários, a tradução para língua inglesa aconteceu depois da publicação da obra de Machado em outros idiomas. Como afirma Nascimento,

apesar do reconhecimento que a autora já possuía, com um grande número de títulos traduzidos em diversos países e prêmios no âmbito nacional e internacional, foi somente após receber o Hans Christian Andersen que Ana Maria Machado teve sua primeira obra traduzida para a língua inglesa (2012, p. 44).

Quanto ao controle quase total do processo tradutório, a relação familiar tão próxima com a tradutora, sua filha, contribuiu para a menor autonomia da tradutora e o maior controle da escritora.

Nascido no Brasil em 1941, João Ubaldo Ribeiro foi jornalista e nunca exerceu a profissão de tradutor. O escritor afirma que a decisão de traduzir, ele mesmo, o romance Sargento Getúlio (1971) para o inglês foi tomada quando o autor teve acesso à tradução feita por um tradutor profissional norteamericano. João Ubaldo considerou que a tradução a ele enviada para revisão demonstrava o alto grau de dificuldade enfrentada por um tradutor que aparentava não conhecer a cultura brasileira e o dialeto usado pelo personagem principal do romance (Antunes 2009, p. 165). Podemos ver, assim, que a aversão do autor à tradução teve papel essencial na sua opção pela autotradução. Além disso, o escritor brasileiro diz que decidiu traduzir o romance de sua autoria "porque era jovem e tinha ilusões" (Ribeiro 1990, p. 3). Em outras palavras, podemos dizer que o escritor desejava o acesso à visibilidade e à existência literárias fora de seu sistema literário de origem que a primeira publicação 
ANTUNES \& WALSH - A decisão de traduzir o próprio texto...

em inglês possibilitaria. As pressões de natureza sistêmica não podem ser negligenciadas, já que também exerceram papel preponderante na publicação de Sergeant Getúlio. O romance foi traduzido e publicado no período em que o governo norteamericano apoiava a tradução e a pesquisa que permitia o crescimento das informações acerca da América Latina (Antunes 2009, p. 168). É certo que Sergeant Getúlio apresentava aos leitores uma visão do povo nordestino e seus costumes.

O segundo romance traduzido por João Ubaldo Ribeiro foi Viva o Povo Brasileiro (1984) e o interesse comercial pode ser apontado como fator determinante, já que o romance teve um enorme sucesso de vendas no Brasil. Outro fator igualmente importante foi a participação de Thomas Colchie, agente de João Ubaldo. Colchie convenceu Ubaldo de que só o próprio autor seria capaz de traduzir o romance repleto de referências culturais para o inglês (Antunes 2009, p. 4). Como Maria Lucia Daflon (2005) destaca, Colchie pode ser considerado uma figura central para a circulação das literaturas brasileira e latinoamericana nos Estados Unidos e em outros países de língua inglesa (p. 87). O próprio João Ubaldo Ribeiro aponta Thomas Colchie como principal responsável por sua carreira internacional.

De fato, a autotradução de Sargento Getúlio para o inglês permitiu que João Ubaldo Ribeiro tivesse acesso a sistemas literários e públicos leitores estrangeiros, já que nenhuma obra de sua autoria havia sido traduzida antes. Entretanto, é inegável que, no caso de João Ubaldo Ribeiro, a autotradução de dois romances de sua autoria para o inglês contribuiu para fazê-lo ainda mais respeitado no Brasil (Gomes 2005, p. 75).

No que diz respeito ao controle absoluto sobre o processo tradutório, como outra consequência da autotradução, ainda que João Ubaldo seja o único responsável pelo trabalho, havia ainda os editores norteamericanos que sugeriam alterações no texto autotraduzido, conforme afirmou o próprio escritor por email.

\section{Considerações Finais}

Neste artigo, discutimos as razões e as consequências da autotradução nos casos específicos de dois autores brasileiros, Ana Maria Machado e João Ubaldo Ribeiro. Percebemos que ambas as razões e as consequências estão intricadas no momento sócio-histórico da autotradução. No caso de Ana Maria Machado, chama atenção a motivação externa da autotradução, o interesse econômico, como resultante 
ANTUNES \& WALSH - A decisão de traduzir o próprio texto...

direta da projeção internacional alcançada pela autora com o prêmio Hans Christian Andersen. No caso de João Ubaldo Ribeiro, salta aos olhos o fato de o período da tradução de Sergeant Getúlio coincidir com o período de maior interesse norteamericano nos países da América Latina.

Particularmente, quanto às consequências, o acesso ao sistema literário da língua inglesa, sistema de prestígio, parece ter uma conotação especial na carreira dos dois escritores brasileiros. No caso de Machado, sua preocupação em acompanhar a tradução de perto evidencia o destaque que a tradução para o inglês tinha para a autora em relação às traduções prévias em outras línguas. Para Ubaldo, o acesso a esse sistema significou internacionalização e (alguma) visibilidade.

Outra consequência diz respeito ao controle do processo tradutório. Os dois autotradutores são exemplos de controle quase total em oposição ao controle absoluto na autotradução. A escritora, apesar de não se sentir preparada para o projeto, garantiu sua supervisão, ao delegar a tarefa à própria filha. O escritor, por outro lado, não teve controle total do processo, porque editores norteamericanos também interferiam na tradução.

Em suma, acreditamos que o presente artigo contribui para preencher a lacuna nos estudos sobre autotradução ao sistematizar as motivações e, particularmente, as consequências da autotradução (e corroborar as que já foram levantadas por outros autores). Considerando que a autotradução não acontece livre de pressões ou desconectada de seu ambiente sócio-histórico, os casos dos dois escritores brasileiros também revelam muito particularmente as relações, interesses e escolhas deflagradas no contato do sistema literário brasileiro com outros sistemas literários, especialmente com os sistemas literários de países de língua inglesa.

\section{Referências}

\section{ANTUNES, M. A. G. O Respeito pelo Original - João Ubaldo Ribeiro e a}

Autotradução. São Paulo: Annablume, 2009.

ASADUDDIN, M. Lost/Found in Translation. Qurratulain Hyder as Self-Translator.

In: The Annual of Urdu Studies, 2008. Disponível em www.urdustudies.com/ pdf/23/24Asaduddin.pdf Acesso em 21/03/2009.

BERMAN, A. The Experience of the Foreign. Culture and Translation in

Romantic Germany, tradução por S. Heyvaert. Nova York: State University of 
ANTUNES \& WALSH - A decisão de traduzir o próprio texto...

New York Press, 1992.

FEDERMAN, Raymond. A voice within a voice: Federman translating / Translating

Federman, 2000. Disponível em http://www.federman.com/rfsrcr2.htm Acesso em 4/5/2006.

FILIPPAKOPOULOU, Maria. Self-translation: reviving the author? In other words, v. 25, Norwich: Pen \& Ink Press, 2005. p. 23-27.

FITCH, B. T. Beckett and Babel. An investigation into the status of the bilingual work. Toronto: University of Toronto Press, 1988.

GOMES, João Carlos Teixeira. João Ubaldo e a Saga do Talento Triunfante. Em: João Ubaldo Ribeiro: obra seleta. Rio de Janeiro: Nova Aguilar, 2005. p. 75103.

GRUTMAN, Rainier. La autotraducción em la galáxia de las lenguas. In: Quaderns, Rev. Trad. 16, 2009. p. 123-134.

HOKENSON, Jan Walsh \& MUNSON, Marcella. The Bilingual Text: History and Theory of Literary Self-Translation, Manchester: St. Jerome, 2007.

\section{KELLMAN, Steven G., Switching Languages. Translingual Writers Reflect on}

Their Craft, Lincoln: University of Nebraska Press, 2003.

KRUGER, Alet, "Translation, Self-translation and Apartheid-imposed Conflict", 2008. Disponível em http://www.multilingua.co.za/pdfs/Kruger_2008_Language _and_Politics.pdf

CASANOVA, P. A República Mundial das Letras. Tradução por Marina Appenzeller. São Paulo: Estação liberdade, 2002.

DAFLON GOMES, M. L. Identidades refletidas. Um estudo sobre a imagem da literatura brasileira refletida por tradução. Dissertação de mestrado inédita. Rio de Janeiro: PUC, 2005.

EHRLICH, S. The Status and Production of Self-translated Texts: Afrikaans-English as a Case in Point. Dissertação de mestrado inédita. Jerusalém: Bar-Ilan University, 2007.

KUNDERA, M. The joke. Nova York: HarperCollins Publishers, 1992.

MACHADO, A. M. Do Outro Mundo. São Paulo: Ática, 2002.

From Another World. Toronto, Canadá: Groundwood Books, 2005.

NASCIMENTO, V. S. A Ação dos Componentes da Patronagem sob a Literatura 
ANTUNES \& WALSH - A decisão de traduzir o próprio texto...

Infanto-Juvenil Brasileira como Fator Determinante para sua Tradução. Do Outro Mundo de Ana Maria Machado - estudo de caso. Dissertação de mestrado inédita. Rio de Janeiro: UERJ, 2012.

RIBEIRO, J. U. Suffering in Translation. In: P.T.G. Newsletter, Portuguese Translation Group (ATA, New York) 3 (3), 1990, Jan/Fev. p. 3-4.

RIBEIRO, J. U. (1971) Sargento Getúlio. Rio de Janeiro: Nova Fronteira, 1982.

Sergeant Getúlio. Boston: Houghton Mifflin Company, 1978.

Viva o Povo Brasileiro. Rio de Janeiro: Nova Fronteira, 1984.

An Invincible Memory. Nova York: Harper \& Row Publishers, 1989.

SANTOYO, Julio César. “Autotraducciones: una Perspectiva Histórica”, Meta (50)3, 2005. p. 858-867.

. Blank Spaces in the History of Translation. In BASTIN, Georges; BANDIA, Paul F. (eds.) Charting the Future of Translation History. Current Discourses and Methodology. Ottawa: University of Ottawa Press, 2006. p. 11-43.

SCHEINER, C. In place of a preface: reading chapter one of Nabokov's Laughter in the dark as a foreword to the English translation. In: Proceedings of the international Vladimir Nabokov symposium, São Petersburgo, Rússia, 2002b. Disponível em http://www.nabokovmuseum.org/PDF/Scheiner.pdf Acesso em 21 jul. 2003. 